\title{
IMPLEMENTING OF 5S RULE IN IRON-STEEL INDUSTRY COMPANY
}

\author{
Deniz Horuz ${ }^{1}$, Selim Çörekçioğlu², Stefan Raskovski ${ }^{3}$ \\ ${ }^{1,2,3} \mathrm{PhD}$ student \\ ${ }^{1,2}$ Doctoral School of Management and Business Administration, Faculty of Economics and \\ Social Sciences, Szent Istvan University, \\ ${ }^{3}$ Doctoral School of Philosophy, Program Ethics and Political Philosophy, Department of \\ Modern and Contemporary Philosophy, Faculty of Humanities, Eotvos Lorand University, \\ E-mail: dnzhoruz@gmail.com ${ }^{1}$, corekcioglu.selim@phd.uni-szie.hu², \\ raskovski.stefan@gmail.com ${ }^{3}$
}

\begin{abstract}
Nowadays, every company cares about reducing their waste and cost. While they are doing that they would prefer to make it effectively and efficiently. That is why the $5 \mathrm{~S}$ rule is recently a more suitable tool to use for companies. In this paper, It was studied how to implement the $5 \mathrm{~S}$ rule in an iron-steel industry company with an interview of a quality engineer who works in this company. This case study was made to be an example for the sector by photographing the before-after situations of $5 \mathrm{~S}$ implementation. Which is carried out in the equipment and manufacturing departments of the iron-steel factory that is operating in Hatay. At the end of the $5 \mathrm{~s}$ implementation, we may say that the risks, that may occur in the factory, are reduced, It helped to save much more time in production, and also the sustainability of the waste products has been formed to use for future needs in the factory.
\end{abstract}

Keywords: Quality Management, $5 S$ rule, Lean Management

JEL classification: D24, L15, M11

LCC: $H ; J A$

\section{Introduction}

Due to the changing economic situation, organizations in many different structures can improve their resources at different times following their business strategies. This often results in the need to do more work using fewer resources (Zerenler \& İraz, 2006). To succeed, businesses must be more productive, reducing waste, and thus reducing costs. Companies should find ways to do what they are currently doing in less time and at a lower cost. One way they can succeed is through the use of the $5 \mathrm{~S}$ rule. $5 \mathrm{~S}$ Principles are very effective in identifying and eliminating unnecessary items as well as increasing efficiency (Karşıyaka \& Sütçü, 2019). There is a lot of information about $5 \mathrm{~S}$ and how it came to be. The popular belief is that the Japanese invented the 5S Methodology because the letter "S" stands for five Japanese words. The principles in 5S were used by Mr. Henry Ford decades ago. It was reported that before 1920, Mr. Ford used CANDO in its production processes. CANDO stands for Cleaning up, Arranging, Neatness, Discipline, and Ongoing improvement. In the 1950s, Toyota representatives visited Ford plants to receive training on automotive mass production methods. The Japanese later adapted the CANDO methods and applied them to the production facilities. Some common words describing the steps in 5S are Sort, Set, Shine, Standardize, and Shine. Various words with similar meanings are used throughout different companies (A.Levinson, 2002). Whatever specific words are used to describe the steps in $5 \mathrm{~S}$, the goal remains the same: to create a clean, tidy, and efficient working environment. (Kanamori et al., 2015) 


\section{Literature Review}

\section{What is the $5 S$ tool?}

One of the most powerful Lean Manufacturing Tools and the cornerstone of a successful application is $5 \mathrm{~S}$. But what is $5 \mathrm{~S}$ and its 5 Steps of Sort (Seiri), Straighten or Set in Order (Seiton), Shine (Seiso), Standardize (Seiketsu), and Sustain (Shitsuke). 5S is a simple tool to organize your workplace cleanly, efficiently, and safely to improve your productivity, visual management, and promote standardized work. (Jiménez et al., 2015)

Most of the other 5S definitions focus on the aesthetic and efficiency gains you have achieved by applying $5 \mathrm{~S}$ and neglect the true purpose of $5 \mathrm{~S}$. Its main purpose is the need to introduce standard operational practices to provide efficient, repeatable, and safe ways of working. By applying Lean Tools, they provide a highly visual workplace, in addition to the standardized work that gives you a stable foundation for creating all your other improvements. One of the most important factors of $5 \mathrm{~S}$ is that problems arise immediately. $5 \mathrm{~S}$ is a process carried out by a team. And it should be managed by people working in the area where $5 \mathrm{~S}$ principles are applied. It is not a tool that can be applied to a region with the cooperation of foreigners. It is a need to know the people within it (Hirano, 1986).

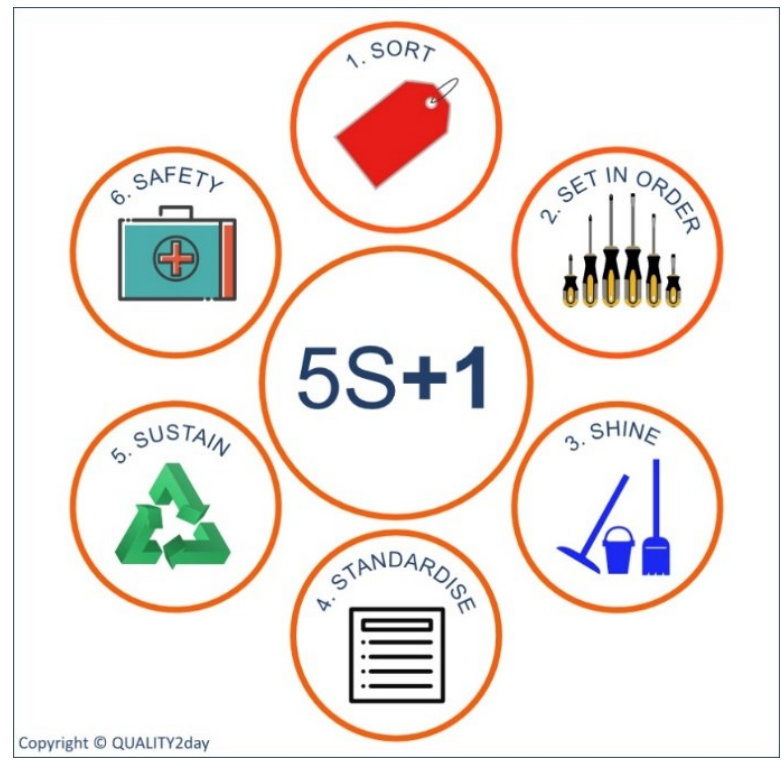

Figure 1.: Steps of 5S

Source: QUALITY2day

\section{How to Implement $5 S$}

\section{Sort}

The first step is sort in 5S. During the sort, the team should review all items in the work area, including all tools, supplies, and mass storage parts. The $5 \mathrm{~S}$ team leader should review and evaluate every item in the group. This will help determine what elements are required to do the job effectively and efficiently. If the item is required for daily operations, it should be labeled and cataloged. If the item is not required, determine how often it is used in the performance of the job in that area. If it is a bulk item, decide on the appropriate amount to be stored in the area and move the remaining amount to the warehouse. Excess inventory is a waste type and should be eliminated during 5S activities. (Randhawa \& Ahuja, 2017) 


\section{Set in Order}

Specify a location for all items that remain in the workspace. Put all the items in their designated places. A frequently cited quote is "A place for everything and everything in its place". During the straightening step, look for ways to reduce or eliminate waste. One form of waste in a process is unnecessary operator movement. For this reason, frequently used tools and consumables should be stored in the work area close to the operator. An effective way to avoid wasting time searching for the right tool is to create shadow boards for all essential tools. Products that are not used frequently should be stored according to their frequency of use. All parts boxes must be properly labeled. The label should contain the part number, part description, storage location, and recommended minimum / maximum amounts. A properly corrected workspace allows the operator to quickly review and verify that they have everything they need to successfully fulfill their tasks. (Matsushita, 2015)

\section{Shine}

The next step is to clean everything in the region and remove debris. To be effective, we must keep the area and related equipment clean. Dirty process equipment may increase the potential for process variability and can lead to equipment failure. Time lost due to equipment failure is considered waste and no added value. A contaminated area can also contribute to safety issues that have the potential to cause injury to a worker. Operators must clean their field at the end of each shift. By doing this, they will likely notice anything unusual, such as oil or lubricant leaks, worn lifting cables, burnt out bulbs, dirty sensors, and so on. (Ene Yalçin et al., 2020)

\section{Standardize}

The fourth step was called the most important step in the 5S process. In this step, we need to develop standards for the $5 \mathrm{~S}$ system. These will be the standards by which the previous $5 \mathrm{~S}$ steps were measured and maintained. In this step, study instructions, checklists, standard studies, and other documents have been developed. Without work instructions or standard work, operators tend to gradually make their paths rather than those set by the team. The use of visual management is very valuable at this stage. Sometimes media coding and standard colors are used. Photos of the area in the standard 5S configuration are usually sent for easier identification of incompatibilities. Operators are trained to detect unsuitable conditions and correct them immediately. Besides, programs should be developed for regular maintenance activities in all areas. (Hossein Hojjati, 2011)

\section{Sustain}

This can sometimes be the most challenging step in the process of five steps $5 \mathrm{~S}$. It is the continuation of the Sort, Straighten, Shine, and Standardize steps. It is the most important step in meeting the need to perform $5 \mathrm{~S}$ on a consistent and systematic basis. During this step, a standard inspection system is generally developed and implemented. The purpose of the continuation step is to incorporate the $5 \mathrm{~S}$ process into the company culture. The company should try to make $5 \mathrm{~S}$ a lifestyle so that the benefits of exercise can be preserved. $5 \mathrm{~S}$ is not a one-time exercise. After the $5 \mathrm{~S}$ Process, it is necessary to become a habit (Gapp, Fisher, \& Kobayashi, 2008). 
$5 S+1$

Some organizations have added steps and named their processes $5 \mathrm{~S}+1$. The additional step taken is safety. The purpose of adding this step is to promote a culture that increases safety by identifying and eliminating any workplace hazard. Also, tools and workstations are selected or designed with the appropriate ergonomics in mind. The emphasis is on the motto "Safety First" at each of the other 5S steps. (Filip \& Marascu-Klein, 2015)

Many companies applied 5S to all areas. The greatest benefits usually occur when $5 \mathrm{~S}$ is implemented as part of a larger lean initiative within the organization. If $5 \mathrm{~S}$ is implemented properly, it can help support your company's lean initiatives and can be a strong incentive to develop a culture of continuous improvement (Shah \& T.Ward, 2007).

\section{The 8 Forms of Waste}

As mentioned earlier, 5S Principles are effective tools to reduce waste, improve quality, improve efficiency, promote safety, and promote continuous improvement. When applying the $5 \mathrm{~S}$ Methods, you should always remember the various forms that waste can take (Ginting et al., 2020):

- Overproduction - To produce more products than necessary or to produce parts faster than downstream processing. Try to produce the right amount at the right time.

- Excessive Inventory - This may be a direct result of overproduction or due to poor purchasing practices. Excessive or unnecessary inventory can spread other types of waste.

- Inappropriate or Non Value Added Processing - Waste arises from the use of the wrong tool, unnecessary processes, or by not using the most efficient processes or tools for the job. Pay attention to the statement "Because we always did this way". The right method and the right tools can reduce waste in the process.

- Waiting - Time and resources might be wasted while waiting for parts, supplies, or information.

- Transportation - Excessive travel or movement of material is wasted. The right planning and process layout can help reduce or eliminate excess transport. Using value stream matching can help the team to fully visualize how much material is traveling.

- Unnecessary Motion - Any movement that does not add value by the operator is a waste. Examine the movements needed to perform the task during your $5 \mathrm{~S}$ exercise. Arrange the workstation so that all tools and supplies are readily available and easily accessible. In some cases, reordering certain processing steps may reduce excessive movement by the operator. You can create a more ergonomic workstation by reducing or eliminating excessive motion loss. Always consider safety first.

- Defects - This waste form is the worst. Producing unsuitable parts or assemblies increases the amount of scrap, reduces processing efficiency, waste machine, process or assembly time, and causes wear of the tool without added value. Faults can also create additional waste in the form of dwell time if downstream operations run out of available parts.

- Untapped Employee Creativity (potential) - Many companies now realize that their best assets are employees. Companies should create an atmosphere where ideas are encouraged. Some of the most successful organizations have created a culture where employees' ideas are truly heard and evaluated. When their good ideas are applied, the employee is recognized and rewarded. You never know where your next great idea will come from (Jakubiec \& Brodnicka, 2016). 
When implementing your 5S program or other lean tools, pay attention to various waste forms. Take action to eliminate waste in your processes. Involve team members and encourage ideas for improvements. Teams will take ownership of the process when they work together to recognize, handle, and eliminate waste and improve their workplace. They are more likely to detect incompatibilities in the future. 5S Principles will slowly become a habit. Then you will start developing the culture of continuous improvement (Jones \& Womack, 1997).

\section{Method and Data Set}

The method of this study, the qualitative research method was adopted, and data were compiled by face-to-face interviews based on a 7-item question prepared in advance. I have interviewed with a quality engineer of the factory.

Data Collection of this study, the opinion of the quality engineer of the company whose name is branded has been examined by the interview technique about the implementing of the $5 \mathrm{~S}$ rule in Iron-Steel Industry Company.

The interview was recorded by a device and the other part was recorded with a note. The interview took 45 minutes in total. The participant wanted to keep the company name and his name hidden. The interview took place in the city of Hatay in Turkey.

Data Analysis, In the interview with the participant of this study, a semi-structured interview form consisting of seven questions was used by the researcher. The opinions of the engineer were transmitted based on confidentiality and coded without giving his name. The coding was determined as an interviewee.

In this study, the data obtained from face to face interview was analyzed by using the descriptive analysis method. The descriptive analysis method was used to analyze the data obtained from a face-to-face interview by describing the interview that was thought to contain very valuable information. Also, the answers obtained from the questions asked during the interview, observations, and document reviews, and the findings obtained from the website were interpreted by content analysis.

According to the descriptive analysis, the data obtained are summarized and interpreted according to the previously determined themes. Direct citations are frequently taken to reflect the views of the interviewed individual. The purpose of this kind of analysis is to present the findings to the reader in an edited and interpreted manner. The data obtained for this purpose are first described systematically and clearly.

\section{Result}

\section{May you briefly introduce your company? Where does it stand?}

Interviewee: It is an iron-steel industry factory. The company started to integrate iron and steel plant in Iskenderun - Sariseki/Turkey Organized Industrial Zone in 1993. 859.000 tons of steel mill per year, with a capacity of 1.024.326 tons of rolling mill according to customer demand; TS, DIN, ASTM, AFNOR, JIS, and other world standards under the production of steel billets and rebar passes. TSE and ISO 9002 certificates received by the company are the most important indicator of the importance given to quality control. 


\section{What is your quality assurance system in your factory?}

Interviewee: The factory has ISO 9001: 2000 Quality Management System Certificate which is accepted internationally. ISO 9001: 2000 Standard is the basis of their quality management system and covers all in-plant applications and all of our employees contribute to this system.

\section{How did you decide to use the $5 S$ tool in your factory?}

Interviewee: Everything was messy and old in the factory. It was hard to find equipment. The personnel, who has been working for more than 5 years, knew where the tools were but new employees were having trouble finding the tools. That is why how we decided to use the $5 \mathrm{~S}$ rule against these problems. We wanted to create a more organized environment using $5 \mathrm{~S}$. Also, we wanted to extend the useful life of the pieces of equipment by sustaining the types of equipment. We did this by maintenance. We wanted to shorten the material search time of employees by using $5 \mathrm{~S}$. We also used $5 \mathrm{~S}$ to recognize missing materials. It helped us to find the equipment easily.

\section{How do you teach the $5 S$ tool to your employees?}

Interviewee: Actually, white-collar workers know what the $5 \mathrm{~S}$ tool for. Our goal is to teach this $5 \mathrm{~S}$ rule to blue-collar employees. To teach the logic of $5 \mathrm{~S}$ to blue-collar employees, first of all, we have given a $5 \mathrm{~S}$ training course in which we explain what is the $5 \mathrm{~S}$ tool and how to use it. Secondly, we have given case studies to improve the understanding of the $5 \mathrm{~S}$ tool. Last but not least, we have given problem-solving examples to clarify every step of $5 \mathrm{~S}$ and show the way how they can solve the issues when they face which related to the $5 \mathrm{~S}$ tool idea.

\section{How do you implement the $5 S$ tool in your factory? Briefly explain, please.}

Interviewee: We have implemented the $5 \mathrm{~S}$ tool through monthly inspection. The factory is divided into separate units. There are 18 different units in total. These units are visited and inspected in the last week of each month. The control of the previous work is carried out. There is also a report on what should be done for the other month. This report shows the activities to be carried out in the units, the activity panel is determined by the actions to be taken and by whom. And on which date it will be re-checked, it is written on the ground that every employee can see.

After the unit check, there are scoring systems for each unit. They update this score after each inspection. If the actions to be made, a high score is given. They also control old actions to ensure continuity. If there is trouble in the old action, points are reduced. Monthly reports on units are written at the end of the scoring. After this, that report, which has scoring on it, is sent to each unit. That report shows, which actions were carried out, what actions should be made, what actions were postponed, and why it could not be done contains information about them per unit. After organizing the whole scoring report, we have selected the 3 most popular actions of the month. That shows us and employees which unit was more successful at the end of this monthly unit checking. We do that to motivate our employees. They can keep their $5 \mathrm{~S}$ attitude effectively and efficiently.

\section{Do you have another implementing way of the $5 S$ tool?}

Interviewee: The factory has a $5 \mathrm{~S}$ red sticker plan. During the extraction process of unnecessary materials, they put a red label on the materials which employees do not know what to do with them while they are debugging. Each unit has a red label area. They leave these materials in 
these red label areas. The purpose of doing that is to prevent the disruption of the current action or work. The materials are placed in the red label area and these materials' waiting time is a week. After collecting those things, we have discussed with the managers what should be done for these materials. At the end of the discussion, these materials are either sold or used in other units. In this way, we ensure the continuity of the materials.

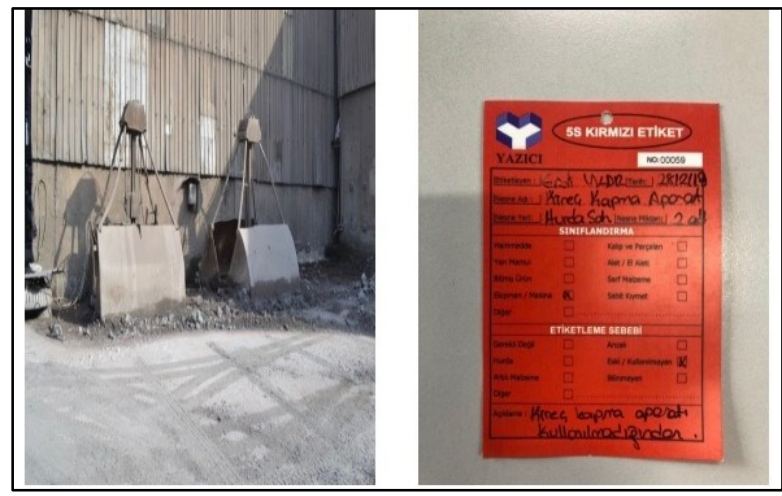

Figure 2.: Implementing of $5 \mathrm{~s}$ with a Red Label for Materials(Sort)

Source: The Report of Examined Factory

\section{How do you show the result to your employees?}

Interviewee: We make a PowerPoint presentation about what we have done monthly for each unit then we publish this presentation on the cafeteria's television screen. Everybody can see the result in that way. They see the whole action with before-after pictures.

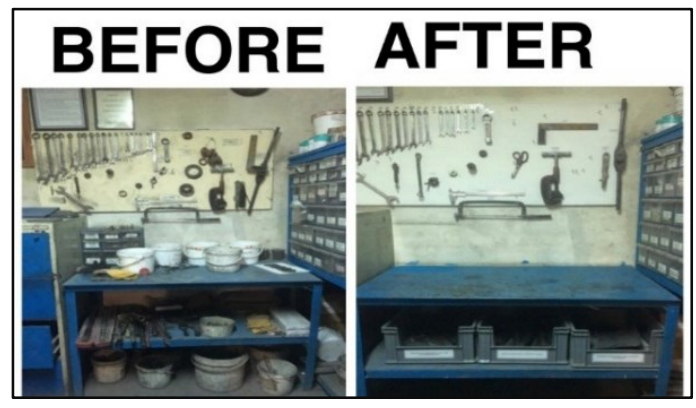

Figure 3.: Implementing of $5 \mathrm{~S}$ in the tool area(Set in Order)

Source: The Report of Examined Factory

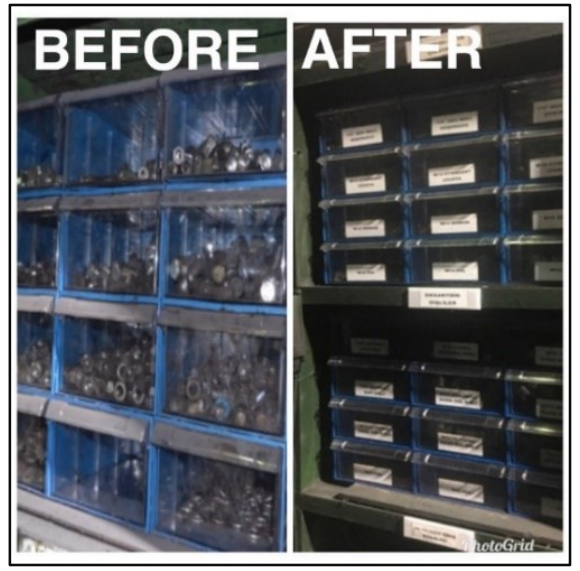

Figure 4.: Implementing of $5 \mathrm{~s}$ in the equipment area(Standardize)

Source: The Report of Examined Factory 


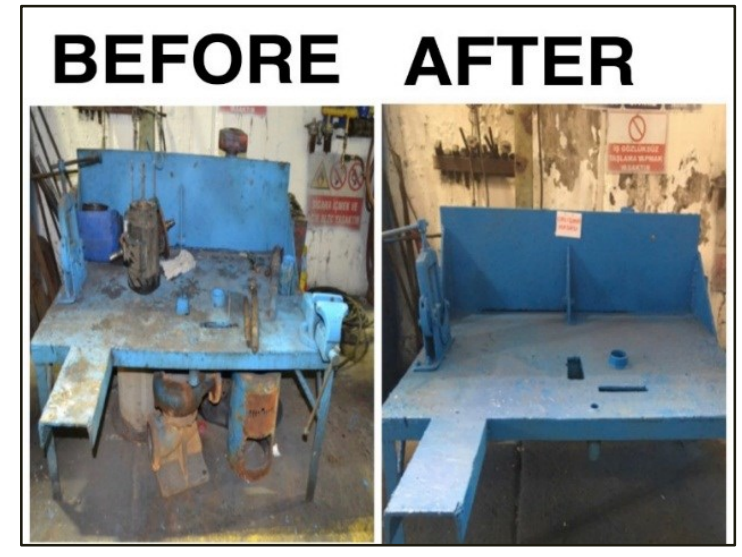

Figure 5.: Implementing of $5 \mathrm{~s}$ in the material area(Shine)

Source: The Report of Examined Factory

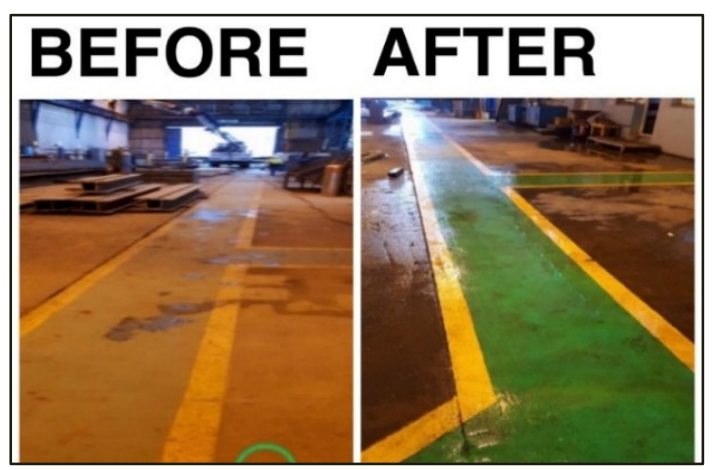

Figure 6.: Implementing of $5 \mathrm{~s}$ in the pathway(Safety)

Source: The Report of Examined Factory

Figures, which are above, are the examples and results according to what the quality engineer was trying to explain during the interview session regarding how they usually manage the actions in the company by using the $5 \mathrm{~S}$ rule. Also, the figures, which came from the factory's report, show us the steps of the $5 \mathrm{~S}$ rule. Furthermore, Figures show how units of the factory are well organized, reducing the time and cost, increasing sustainability, and decreasing the risk in the workplace after implementing the $5 \mathrm{~S}$ rule.

\section{Conclusion}

The 5S study of this paper, describes the 5S (seiri, seiton, seiso, seiketsu, and shitsuke) method implemented to improve the workplaces, to increase the working environment quality, to eliminate or reduced mistakes, to sustain the industrial process performance. After having interview answers and various before-after pictures, which have been taken from the factory, are proofing those sentences. Those also show what was the point of the factory to reach while they were implementing the $5 \mathrm{~S}$ rule. Additionally, the answers of the interviewee show us that the advantages of implementing the $5 \mathrm{~S}$ method in the factory are: development of a qualityconducive working environment, eliminate errors, mistakes and problems are visual, reduction of waste, reduction of waiting and searching time, transparency and clearness of workflow and workplaces, establish standards (everyone knows exactly where to find things), work safety and ergonomics of all employees. Those advantages confirm that they effect generally the factory's process positively. 
According to the factory's quality engineers' report, after implementing the $5 \mathrm{~S}$ method at the factory, the factory has been achieved the following results:

- $\quad$ Preparing workshops on 5S topics (agenda, participants, objectives, etc.);

- Moderating the 5S workshops;

- Communicating the 5S standards catalog;

- Supporting on training and implementation of the new 5S standards;

- Supporting production workers in compliance standards;

- Supporting the development of personal service on 5S topics;

- Drafting the standardization form of process work and the 5S audit form;

- Training for 5S audit and process confirmation;

- Achievement the process confirmation of workplaces and the 5S audit;

- Supporting the process confirmation achievement;

- Establishing the reporting mode of 5S activities;

- Performing and continuous improvement of the 5S method implementation.

\section{References}

1. A.Levinson, W. (2002). Henry Ford's Lean Vision: Enduring Principles from the First Ford Motor Plant. Productivity Press.

2. Ene Yalçin, S., Akin, S., Elmas, B., Eren, M., \& Gündüz, T. (2020). Çelik Boru İmalatinda Hazirlik Sürelerine Yönelik Yalin Üretim Ve Smed Çalişmasi. LEAN PRODUCTION AND SMED STUDY FOR SETUP TIMES IN STEEL PIPE MANUFACTURING., 31(1), 87-104.

3. Filip, F. C., \& Marascu-Klein, V. (2015). The 5S lean method as a tool of industrial management performances. IOP Conference Series: Materials Science and Engineering, 95(1), 012127.

4. Gapp, R., Fisher, R., \& Kobayashi, K. (2008). Implementing 5S within a Japanese context: an integrated management system. Management Decision, 565-579.

5. Ginting, S. E. F., Ramadhani, V. B., Tarigan, U. P. P., A., G., Simarmata, E., \& Saragih, L. L. (2020). Implementation of Lean Service and 5S Methods to Increase The Efficiency of Service Time in Fire Department... AIP Conference Proceedings, 2227(1), 1-7.

6. Ghagare, S. D., Desai, A. A., Patil, R. B., \& Siddha, U. Y. (2017). 5S IMPLEMENTATION IN SMALL SCALE INDUSTRY: A CASE STUDY. Adarsh Institute of Technology and research centre, 23-29.

7. Hirano, H. (1986). 5S for Operators: 5 Pillars of the Visual Workplace. ISBN-10: 156327-123-0 : Productivity Development Team.

8. Hossein Hojjati, S. M. (2011). Implementing 5s System in Persia Noor Factory. International Journal of Industrial Engineering, 18(8), 425-431.

9. Jakubiec, M., \& Brodnicka, E. (2016). KAIZEN CONCEPT IN THE PROCESS OF A QUALITY IMPROVEMENT IN THE COMPANY. Research on enterprise in modern economy - theory and practice, 89-101.

10. Jiménez, M., Romero, L., Domínguez, M., \& Espinosa, M. del M. (2015). 5S methodology implementation in the laboratories of an industrial engineering university school. Safety Science, 78, 163-172.

11. Jones, D. T., \& Womack, J. P. (1997). Lean Thinking: Banish Waste and Create Wealth in Your Corporation. Journal of the Operational Research Society, 48(11), 1148-1148. 
12. Karaman, M., Karatepe, H. K., \& Kuşçu, F. N. (2019). Sağlık İşletmelerinde Performans Değerlendirme ve Ölçme Yöntemleri Hakkında Bir Derleme Çalışması. Yönetim Ekonomi Edebiyat İslami ve Politik Bilimler Dergisi, 153 - 171.

13. Kanamori, S., Sow, S., Castro, M. C., Matsuno, R., Tsuru, A., \& Jimba, M. (2015). Implementation of $5 \mathrm{~S}$ management method for lean healthcare at a health center in Senegal: A qualitative study of staff perception. Global Health Action, 8(1), 27256.

14. Karşıyaka, O., \& Sütçü, A. (2019). Mobilya Üretim Süreçlerinde Verimliliği Artırmaya Yönelik 5S Uygulamaları. Bilge International Journal of Science and Technology Research, 87-101.

15. Matsushita, H. (2015). What Is 5S-KAIZEN? Asian-African Transnational and Translational Community of Practice in Value Co-creation of Health Services. In K. Kijima (Ed.), Service Systems Science (pp. 129-143). Translational Systems Sciences series, vol. 2. New York and Heidelberg: Springer.

16. Randhawa, J. S., \& Ahuja, I. S. (2017). Evaluating impact of 5S implementation on business performance. International Journal of Productivity and Performance Management, 66(7), 948-978.

17. Shah, R., \& T.Ward, P. (2007). Defining and developing measures of lean production. Journal Of Operations Management, 25(4), 785-80.

18. Zerenler, M., \& İraz, R. (2006). Japon Yönetim Anlayışı Ve Şirket Ağları (Keiretsu) Analizi. Selcuk University Social Sciences Institute Journal, (16), 757-776. 